\title{
Towards a Cultural Economy Paradigm for the Australian Wine Industry
}

\author{
DAVID AYLWARD
}

\begin{abstract}
The twenty-first century wine industry is a very different one from that which dominated operations in the 1980s and 1990s. Production, distribution and marketing of wine are now colonised by an array of complex and intersecting dynamics. Primary among these is a growing demand among consumers for value-added qualities. Particularly in mature markets, standardised, commodity-style wine is failing to satisfy an increasingly educated consumer base. What is required now among a number of New World producers is an understanding of the way in which wine's cultural and economic qualities can be woven into a more enriched fabric. This would not simply add cultural elements to an economically oriented product. Rather, it would weave individual and community values, passion, care, identity, and terroir together with the more tangible aspects of production, distribution, price-points and marketing.

Such an enriched 'fabric' will be referred to throughout this paper as the cultural economy of wine. It will be argued that the Australian wine industry, as a case study, must not only reconfigure its operational structure to reflect these qualities, but must change the way it thinks collectively about its product if it is to remain competitive in an increasingly complex environment.
\end{abstract}

Keywords: wine; industry; cultural economy; SMEs; localisation

\section{Introduction}

Beginning in the early 1980s the Australian wine industry negotiated the successful transition from a domestic wine supplier to the world's fourth largest exporter. In fact, between 1999 and 2005 it dominated popular 'commodity' price-points in two of the largest wine markets - the UK and the USA. It had developed a reputation for delivering fruit-driven, value-for-money wine to commodity markets for immediate consumption. Its recipe was based on mass production, standardisation and scientific imperatives. For a time, it was very successful. Some less sympathetic observers labelled it the 'coca-colarisation' of wine, claiming that short-term 
economic thinking had expunged the 'art' of winemaking and reduced the practice to little more than formulaic, assembly-line production. ${ }^{1}$ Many believe they were correct.

In fact, it is the previous short-term thinking that is now haunting the Australian industry. Throughout the late 1990s and early millennium years the international wine industry's evolution was accelerating into a complex landscape of supply and demand modes. Markets were reconfiguring into new categories where the competition was moving beyond price to focus instead on product. The entrance of additional producers on a large scale and the increasing influence of wine writers, commentators and consumer expectations were driving trends. Such trends had originated with simple product differentiation but were now developing into a quest for product story, a wine experience, and an appreciation for its cultural qualities. $^{2}$

The emergent message was that wine was being viewed less and less as a commodity and more as a process that delivered a range of experiences to the demanding consumer. Wine as a cultural asset was gaining traction. Small family producers within France, Italy and Portugal that had lost market share to fashionable New World producers throughout the 1980s and early 1990s, were enjoying a renaissance as educated consumers sought out wines of interest and character, wines in which the multinational producers of the New World had little interest or expertise. $^{3}$

In many ways these changes were a natural process of extension. For decades the international wine industry had been educating its consumers about its product. It had led them on a journey that included more sophisticated advertising, routine competitions and tasting scenarios, a wealth of written material on different regions and their styles, and greater levels of accessibility through distribution. The industry had brought wine, in all its variations, into the home and guided the consumer in its choice. Two-dimensional supply and demand routes of the 1980s were no longer meeting the needs of this complex new environment. Just as with food, the consumer had moved away from the traditional 'Chinese meal' to discover and experience a vast array of culinary delights. These 'delights', and consumer affluence to match them, meant that the wine evolution would continue. That evolution was now synonymous with an enhanced cultural recognition and appreciation which demanded smaller production batches of artisan quality. ${ }^{4}$

In such an environment the Australian wine industry was being increasingly restricted by its previous success. Its centralised structure (due primarily to the nationalised collection and distribution of a research and development levy), together with a national export and branding strategy, restricted its capacity to adapt. Risk aversion became the dominant operating paradigm as the framework established by the industry's largest producers became more disconnected from current requirements. ${ }^{5}$ Commodity markets remained the target of the industry's major producers and as resources followed their interests, small and medium wine producers were forced to align their own activities with those of their largest peers. The result was that many smaller producers were forfeiting their individuality and differentiation to compete at a disadvantage in the mass wine markets of the world. $^{6}$

The deterioration in the industry's situation continues with operating, distribution and marketing patterns being shaped by an adherence to structures and decision-making which are unsuited to new and complex demands. ${ }^{7}$ The provision of research and development (R\&D) extension, export guidelines, quality assurance, 
governance, and industry branding are all controlled by central authorities and therefore continue to reflect the broadest priorities. ${ }^{8}$ Within such a framework, planting, harvesting and production methods also followed generic approaches, often spanning multiple regions and even states. ${ }^{9}$

International markets are now embracing a level of differentiation for which Australian producers are ill-equipped (for example, 74\% of participants in a 2006 study believed that the Australian wine bodies did not recognise the importance of a differentiated product or market). ${ }^{10}$

Belatedly, and after much public examination, the industry is now attempting to redress its most obvious areas of disconnection. At least in rhetoric, it is undertaking a realignment exercise in which the focus is shifting to premium products directed towards premium markets. This paper will argue that the Australian wine industry must first gain a truly cultural understanding of its product before any economically meaningful or lasting restructure can occur. The industry must pursue more intimate connections between the cultural and economic values bound up in the production of wine and recognise that these values are not antithetical, but, in fact, interdependent cornerstones of a sustainable wine industry. Finally, the industry must reassess its emphasis on winemaking as a science, an emphasis that has often encouraged producers to 'disengage' from their product and relegate it to 'assembly-line' production.

\section{Cultural Implications of a Science-based Model}

In Australia and other New World wine regions 'science' has enjoyed a dominant and prestigious place in wine production. National wine research institutes have risen to prominence as scientific methods of planting, harvesting, soil management, fermentation, maceration and ageing have been increasingly introduced to the industry's psyche. As their prescriptions for vine and soil disease, grafting techniques, irrigation efficiencies, flavour and filter technologies, and recipes for fault-free, standardised products grew in use and effectiveness, so too did their reputations. $^{11}$

Centralised resource structures also ensured that the research institutes' acceptability was promoted at every level. For example, the Australian Wine Research Institute (AWRI) based in Adelaide, South Australia was 'anointed' by the industry's Grape and Wine Research and Development Corporation (GWRDC) as the primary R\&D provider for Australia's wine producers. In such a position, the AWRI's R\&D agenda was legitimised through industry-sponsored programmes, a mandated levy system, and government sanction. The Californian wine industry witnessed a similar 'scientific revolution' with the emergence of UCDavis as the leading authority on all aspects of viticultural and oenological development. $^{12}$

These two institutions in particular, learnt from, led, and often competed with each other in the pursuit of pure and predictable products. In New World regions such as Australia, California and South Africa, 'scientific credibility' was to become a benchmark of the industry's R\&D performance, and in fact, a pseudo-benchmark for the product itself. The very essence of wine production was now guided by scientific measures and criteria. It was a movement that was being hailed by much of the New World as a revolution that would 'shake the wine world', an exactness that would deliver faultless, uniform products, vintage after vintage to a growing market. Traditionalists, however, were already identifying the flaws. 


\section{A Product Too Clean}

To ensure that the market was supplied with faultless wine, New World producers began focusing more and more on the purity of the end-product. And for them, purity equated with a lack of sediment. If a wine contained residues it was considered unclean and subject to tainting. ${ }^{13}$ French, Italian and Spanish producers were scorned by their New World counterparts for what was perceived as quaint but hopelessly outdated production methods. They were criticised for unhygienic barrels and storage tanks, improper treatment of equipment and a lack of 'appropriate' filtration. The fact that many of their wines contained sediment was viewed as an anachronism that stood in the way of progress.

New World industries were instead adhering to the orthodoxy of 'sediment removal at all costs'. Industry think tanks and regulators were promoting filtration as integral to good wine production, a practice which resulted in its overuse by a large percentage of producers. In fact, for some, the approach was one of 'more is better'. It was not uncommon for winemakers to filter two, three and even four times in an attempt to guarantee complete 'purity' for their product. Cross-flow and 'dead-end' flow membranes became fashionable and culminated in filters so fine that the liquid had to be forced through at high pressure. ${ }^{14}$

While customers buying in the commodity price points saw this as a positive way of delivering sterilised products to their dinner tables, more traditional operators were horrified at the way wine was being depleted of its character (interview participant, 2007). Their argument, and one that carries significant weight, was that multiple filtration had become a substitute for good winemaking practice. It was, in many cases, being adopted to rectify flaws in the production method-flaws that were often the result of inexperience or a lack of quality control. ${ }^{15}$ Filtration encouraged laziness in the winemaking process and tended to mask incompetence. ${ }^{16}$ More importantly, it encouraged distance between winemakers and their product. The intimate coexistence of human and environmental input was, to an extent, being eroded.

Apart from this cultural depletion, there was the impact on the product itself. There was growing concern among buyers of Australian wine, including its largest-Tesco - that the industry was becoming fixated with 'clean' wine. It was a fixation that was seen as producing pleasant, consistent, but ultimately, bland wine. ${ }^{17}$ Atkins observed that 'Australia doesn't produce faulty wines, but it's the blandness which is almost depressing. In the under (\$A17) market, individuality has almost disappeared'.18

\section{'Coca-colarisation'}

A chorus of criticism is emerging about the production methods of New World wineries, particularly in Australia and South Africa. Many Australian producers are now joining this chorus but because of the cultural and operational framework of their host industry, are reluctant to revert to more traditional, and what they see as more attractive, methods. ${ }^{19}$ In Australia, the largest wine producers, in partnership with national wine associations, have locked industry participants, their operation styles, and their reputations into service of rigid price points within the commodity sector, namely AUS\$8 and below per unit. While this strategy aligns with the supply and demand climate of the 1980s and 1990s, it is failing to satisfy now rapidly differentiated product demand and price points. ${ }^{20}$ 
As a number of SME wine producers claimed in interview, the formulaic production methods introduced by the largest of Australia's wine producers and reinforced by such national bodies as the Australian Wine Research Institute are creating this coca-colarisation of wine. Just as soft drink companies use large-scale assembly lines and tested formulas to produce rigidly uniform drink products, so does Australia's wine production increasingly depend upon standardised methods that create highly similar wine styles. Coca-colarisation of wine reduces the product to a commodity status in which the emphasis is on volume sales in mature markets, and penetration of emerging markets. What Australian producers are now being told by these mature markets, however, is that their consumers' palates have become more educated and more discerning. They no longer want a mass produced product that lacks terroir, character, or distinction in taste. ${ }^{21}$

The centralised structure of Australia's wine industry has meant that it has so far been unable to respond to these new demands. ${ }^{22}$ The production orthodoxy that has pervaded the industry since its success in the 1980s and 1990s has further retarded the industry's ability to provide flexible responses. Successful traditionalists within the industry, who in fact rival the best winemakers of France and Spain, remain culturally isolated within a system still intent upon standardisation and ambiguous geographic indicators. While rhetoric supports their operations they remain on the periphery in terms of decision-making and representation.

\section{Geographic Indicators}

In 2008 the ambiguity of Australia's geographic indicators remains a major constraint to the industry's capacity for differentiation. It is also a significant contributor to the perception that Australian wine is mass produced from multiple regions and has little or no story to tell. At the same time that French producers rely on their Bordeaux or Burgundy affiliation and progressive New World producers from California rely on Napa or Sonoma branding to command high prices for their wines, the Australian industry remains recalcitrant. For example, industry associations are now considering a 'western super-zone' geographic indicator that will rival the infamous South-Eastern Australian indicator. This would stretch from South Australia, encompassing regions of that state to incorporate the entirety of Western Australia, a move that would blend such iconic regions as Margaret River with the unbranded areas of Swan Valley and Geographe. Such a move would of course dilute any regional characters, the particularly strong terroir of Margaret River and further diminish the ability to command anything other than commodity level value for the region's wine. In an era when industry spokespeople are heralding a restructured and differentiated approach, the move tends to undermine confidence in their capacity for meaningful change. ${ }^{23}$

Again, it seems responsibility for such decisions rests with Australia's largest wine producers and the industry's protection of their interests. As major levy contributors, the needs of the industry's largest producers must be catered to, and their interests dictate that geographic boundaries remain obscure. The science behind this is that at the volume end of the market 'Brand Australia' remains a selling point and the best way to maintain such branding is to ensure multi-state geographic regions stay in place.

The long-term economic viability of this 'science', however, is highly questionable. Peter Fuller's comment on the situation is 'that the least persuasive of economic arguments (is) that big is always better'. ${ }^{24}$ As numerous commentaries and 
studies have demonstrated, consumers are moving beyond the 'Brand Australia' framework, instead looking for regional wines with strong stories and distinction. ${ }^{25}$

This is being clearly illustrated by the continuing fall in value-per-item within the volume categories of the market and the increasing value of wine in higher price points (above A $\$ 12$ per litre). In Australia's case, such a trend is now alarming the industry. Within the United Kingdom, Australia's largest and most mature wine market, the value-per-litre of Australian wine has been falling consistently since $2003 .^{26}$ In the July 2008 period, value fell another 3.1\% as these more discerning consumers continued to seek out wines with a sense of place, and distinct characteristics. ${ }^{27}$ In fact, in a scenario not unlike that of the tobacco industry in the 1970s, the only markets where Australian wine is now enjoying consistent increases in value-per-litre are the nascent ones of China, India, and South-East Asia, in which new drinkers are only just beginning their wine journey and are not yet known for their discrimination. ${ }^{28}$

Perhaps the best argument against Australia's economic 'logic', however, is what may be termed the 'Bordeaux model'. There are approximately 10,000 producers in the Bordeaux region but less than $1 \%$ of these are AOC classified, with reputations for producing high quality wines. ${ }^{29}$ The remaining $99 \%$ produce a mixture of poor, average and good quality wines that would rank below those of many Australian producers. Yet these French producers derive enormous benefit in reputation, marketing and price-points from their elite AOC peers. This small group of AOC classified producers have delivered the reputation of 'fine wine capital' to the Bordeaux region. ${ }^{30}$ In the wine world this 'trickle down' effect actually works.

Unfortunately, the Australian industry's strategy of 'market stretch'-hoping the commodity reputation will draw greater recognition to the industry's finer wines-does not demonstrate the same momentum. International consumers remain unconvinced of Australia's ability to deliver wines beyond the commodity sector. Mass plantation and harvesting, multi-region blending, over-filtration, standardised production methods, and ambiguous geographic indicators do not instil confidence in the industry's capacity to service a differentiated market.

\section{Science, Economics and Cultural Depletion}

One may, in fact, argue that the past 25 years of policy and practice within the Australian wine industry reflects the dominance of scientific and economic 'determinism' at the expense of cultural development. In this context, 'determinism' is referred to as the non-contextual pursuit of scientific remedies and twodimensional economic models. The rise of science as a dominant paradigm and its blending with insular, economic goals within the industry has created an operational landscape that is failing to align with the complex, multidimensional landscapes of international wine markets.

This paper now extends previous conceptualisations by the author on alternative winemaking processes and product differentiation by framing these elements within a 'whole systems' cultural economy context. Such a context moves beyond the problems of product standardisation to address implications of limited thinking and strategies by those who control the industry's future. The argument is that under a cultural economy framework, thinking needs to evolve from singly priorities of financial return on given products to a value-driven approach in which both cultural and economic qualities are built into the entire winemaking process from conception to consumption. ${ }^{31}$ The paper argues that the failure to align this 
thinking with an evolving demand landscape can be traced to a growing disconnection between the science and economics of winemaking on the one hand, and the product's lack of cultural asset value on the other. According to a high percentage (78\%) of interviewed SME wine firms, Australia's national wine associations have largely been captured by the notion that providing value-for-money, commoditystyle wine should be the industry's main priority. ${ }^{32}$ These associations are failing to articulate the pursuit of individual stories, a sense of place, and authentic practices, as well as the human and natural elements of terroir. They are failing to recognise the cultural fabric that must weave itself through the entire supply chain of winemaking, from vine to bottle, if it is to emerge as a cultural asset.

To treat the product simply as a saleable commodity is to neglect its highly valuable cultural and anthropological dimensions and the role it plays in the binding of its producer communities. Don and Petie Kladstrup draw attention to wine's intricate connections to people and place in their account of a small French vigneron community:

Life was dictated by the vines and Mother Nature. Vignerons didn’t just work the earth, they were riveted to it, their attachment almost religious in its intensity. Caring for the vines was a sacred trust, for each vine had its own story, evoking memories of ancestors who had labored there before. ${ }^{33}$

This theme will underpin the conceptual framework and discussion following in the paper.

\section{Methodology}

The current paper was based on outcomes, and particularly thinking, that emerged from a number of empirical studies throughout 2006 and 2007. Survey samples consisted of between 100 and 200 boutique, small and medium-sized wine operators, with sub-samples of between 10 and 25 selected for in-depth interviews. All survey firms were selected using a stratified random sampling technique. Four states were covered-New South Wales, Victoria, South Australia and Western Australia-and care was taken to ensure all the major wine regions in these states were well represented. In addition, there was careful sampling according to size, so that boutique, small and medium-sized firms were equally represented. Only exporting firms were included and in each case, either the CEO or the Marketing Manager was surveyed/interviewed.

Survey questions were primarily designed for Likert-scale responses (1-5) but were also supplemented with open-ended, qualitative questions. These qualitative questions were designed to 'unpack' some of the more detailed issues concerning respondent thoughts on branding, regionalisation, differentiation, cultural development of the product, and individual operational and marketing strategies.

In addition to empirical studies, the author has conducted extensive literature reviews on cultural asset mapping, directions in the international wine industry, and the economics of differentiation. He has supplemented this literature with indepth discussions involving highly respected strategic thinkers within the industry, such as Brian Croser and Professor Jim Hardie. The paper represents the distillation of these empirical studies, literature reviews, discussions and the author's own in-depth analysis over a number of years. 


\section{Conceptual Framework-The Cultural Economy of Wine}

... if we take what ecologists might call a 'whole systems' view ... we could bring the economy ... and culture ... together in a single system where interaction and feedback effects were acknowledged, and where in particular the dynamics were made explicit. By conceptualising the interactions between 'culture' and 'the economy' in this way, we might transcend the narrow focus of looking simply at the economy as a self-serving entity, or at culture as bearing no relationship to anything but itself, and replace these piecemeal models with a broader interactive framework in which all relevant economic and cultural variables could be accounted for simultaneously. ${ }^{34}$

Such a concept builds on traditional theories of cultural capital provided by thinkers such as Bourdieu, Guillory and Hoegh-Guldberg. ${ }^{35}$ Their conceptualisations rest upon the premise of independent or segmented variables, whereby economic capital and cultural capital are seen as two distinct and self-contained entities that can and should complement one another. Rather than economic capital being all pervasive, these theorists argue that new paradigms can be constructed in which economic, natural, and cultural capital can each deliver benefits to the other, creating a value-added system of production and marketing. Holden argues that a new language needs to be created to account for the non-measurable aspects of culture. Correctly, he points out that 'those things that are easy to measure tend to become objectives, and those that are not are downplayed or ignored'. ${ }^{36}$ This recognition may go some way to categorising 'culture' primarily in terms of icons, buildings, or performances, as many of Holden's contemporaries do.

What becomes clear in the above approaches, however, is that their attempts to measure and justify cultural capital often result in an almost paternal subjugation to economic viability. ${ }^{37}$ Both economic and cultural capital is presented as selfcontained packages through which others can be utilised and attached as situations demand. The key interpretation in these theories is utility, a purely economic understanding of how tangible items, artefacts, or products can be pulled together to create a product or service of greater value. ${ }^{38}$ This is where subjugation becomes almost inevitable.

Because of these theories' dependence upon tangible evidence and, therefore, economic utility, they have difficulty in addressing the 'fabric of culture' that is attached not to buildings, icons or performances, but to community interaction, collective and individual belief systems, a product's anthropological value, or the sense of place and purpose that becomes inherently bound within that product's development.

Although Throsby also adopts classical cultural distinctions in much of his text, he recognises intangibles such as 'ideas, practices, beliefs and traditions' ${ }^{39}$ In the opening quote of this section he even advocates the interaction of economic and cultural value. The conceptual framework for this paper is centred on such a 'whole systems' approach or what will be referred to as the cultural economy of wine production.

This concept extends beyond the independence of economic and cultural capital and as importantly, the rules concerning cultural tangibility. Instead, it provides an understanding of the cultural/economic fabric that weaves such values as aesthetic, historical, social and symbolic with production, distribution costs, price-points, and market value. ${ }^{40}$ Necessarily, therefore, the concept includes both tangible and 
intangible patterns based upon the end product itself (tangible), and the customs, approach, heritage, and symbols (intangibles) that attach themselves to the product on its journey from conception to consumption.

In this way the cultural and economic qualities of a wine product, for example, can only create market value by coalescing in a complementary fashion without subjugation of one element by another. It is critical that the wine's story, its growth territory, and its real and symbolic connections to the local community become a part of its overall 'message' to the consumer. Just as critical is the notion that the 'tangible' methods of the wine's production, distribution, and marketing reflect these cultural markers and build their value into the overall 'package'. Such coalescence is what is meant by the cultural economy of wine. ${ }^{41}$

\section{New Paradigms for Success}

In the case of the Australian wine industry, cultural and economic elements need to be contextualised in order to make effective contributions. This means that the elements themselves require definition by the industry and acceptance among its producers and consumers alike. The industry and its stakeholders need to change the very way they think about their product. Currently, much of the industry regards wine as little more than a saleable commodity. Relatively few in the Australian wine industry view their product as an expression of their belief system, a representation of their commitment, their passion, and unique 'ecology'.

It appears that a majority of small and medium-sized producers, however, want to move towards such a model. ${ }^{42}$ In a series of empirical studies carried out by the author over the period 2005, 2006 and 2007, between 75\% and 88\% of respondents (each study surveyed at least 100 respondents and up to 200 respondents) believed that the future success of the industry depended upon a localisation of $R \& D$, resources and branding. Less than $45 \%$ of respondents, however, believed that the national industry associations were genuine about pursuing such a model. ${ }^{43}$ In other words, the producers are not necessarily choosing the 'commodity' route for their product, but rather, are enduring it under a system controlled by shared interests of the national wine associations and the industry's multinational corporations. These interests continue to separate economic and cultural elements to an extent that the industry has become locked into a delivery mode that is increasingly disconnected from the markets it services.

Small to medium wine producers (approximately 92\% of surveyed producers within the industry) are calling on industry associations to recognise and promote the naturally localised characteristics of wine. They are asking the industry to implement sensible geographic indicators that reflect regional differences in soil, climate, and grape suitability, rather than the ambiguous indicators that are currently in existence. They are asking for a galvanising rather than diluting of regional identity. They are asking for region-specific extension programmes that support local and unique growing and production characteristics. Most importantly, they are asking for a differentiated approach to distribution and marketing of their wine, where product 'stories' can be told and a sense of place enshrined.

In effect, these producers are identifying the cultural economy of wine production. Operators at the so-called 'coal face' want to move towards the phenomenon that Hugh Johnston refers to as 'charisma in a bottle'. ${ }^{44}$ They are understanding the need to adapt to commercial environments built around an intricate set of tangible and intangible qualities. What they are yet to achieve is the anthropological 
understanding that percolates through so many of Europe's traditional wine regions. It is this quality that can be woven so effectively and completely into a highvalue end-product. ${ }^{45}$ The intangible fabric of meaning, romance, heritage, and symbolic value can represent the cultural dimension of a product unique in its locality, its production methods, and its place among consumers. There is no separation of values. There is, instead, a seamless presentation of quality, care, passion and commercial significance. As Adolphe Brisson says of champagne 'It resembles us, it's made in our image ... It bubbles like our spirit, it is piquant like our language, it sparkles and chatters and is constantly in motion'. ${ }^{46}$

Of course such reform must extend from thinking into action. Specifically, in order to create a seamless integration of cultural and economic qualities, the treatment of the wine through its various production processes must demonstrate a respect for these qualities. This requires a substantial reconfiguration of wine industry practice.

For example, selection of site and grape variety should be dependent upon characteristics such as appropriate climate, soil, gradient, and latitude, rather than simply a perceived under-supply in the market. Planting and spacing methods should be focused on delivering smaller, higher quality yields that are truly indicative of their terroir. Harvesting should be attuned to these yields and the pursuit of quality. A primary aim should be to maintain integrity of the fruit at each stage so that damage is minimised and respect for the product is transferred from the vine to the crusher and fermentation tanks. The next stage is the press, where gently basket pressing has again become fashionable, and of course, the most consistent with maintaining product integrity and subtlety. But its benefits are largely neutralised if the fruit has undergone the unceremonious thrashing of mechanical harvesting beforehand. From the type of barrel selected for ageing, to the length of time the wine is left to age, its racking, its method of bottle closure and finally, its storage, there must be a consistency in care, and attention to what the final product will symbolise.

In a cultural economy framework, all such factors would work in concert with the ownership, distribution and marketing of the end-product. But the structure of the wine industry as a whole must be conducive to the behavioural change. In this way structure establishes the behavioural environment within which such changes can be implemented and endorsed. Stakeholders simply cannot move effectively towards a new framework for their product while the broader industry continues to separate and subjugate these qualities under an economic determinist agenda. It is now critical that Australia's national wine industry associations recognise the changing contours of the international landscape and adjust their operating frameworks accordingly. SME wine leaders who are pursuing a cultural meaning for their product, must have their behaviour accepted by the broader industry. ${ }^{47}$ They need to operate securely and purposefully within an environment that nurtures intimate attachment of cultural and economic qualities, a type of environment that was born in the Champagne region of the 1860 s. $^{48}$

In fact, so evocative was this environment that the term 'champagne' was included for the first time in the French dictionary, defined 'as a wine produced by art but something more than wine'. ${ }^{49}$ The dictionary further warned 'that champagne's capricious nature must be treated with respect and humility for, in the wrong hands, its nature can be forced and reduced to nothing more than a means of making money, ${ }^{50}$ This single sentence captures the essence of why a cultural economy is critical to the Australian wine industry. It shows where the industry is 
now, and the direction in which it needs to move. Currently, the Australian wine industry tends to treat its product 'as nothing more than a means of making money'. What it must move towards is treating the product with the 'respect and humility' that is intrinsic to value-value that displays the cultural and economic qualities of its composition.

\section{Concluding Remarks}

The Australian wine industry is indeed facing a crisis. It must now choose whether to continue along a path of volume dependency, in which mass production, distribution and marketing supply a mass market of commodity style wine, or whether to embrace the cultural economy of wine in what has the potential to add an entirely new dimension.

If it continues along the dependency path, its sustainability is uncertain at best. Price-sensitive competition across all aspects of wine production will ensure a relentless reduction in profit margins and reputation. Other New World producers now have the 'science', and economy of scale, and can often produce equal or better wine for cheaper price-per unit costs. As Brian Croser would say, this kind of competition would guarantee nothing more than 'a race to the bottom'. 51

If, however, the industry embraces the cultural economy of wine it also embraces the opportunity to reconfigure its organisational structures and products in a way that will enrich both their aesthetic qualities and their financial viability. It would provide a cultural-economic 'package' in which new dimensions would add dramatically to the industry’s potential for creating real value.

\section{Notes and References}

1. D. Aylward, 'Interviews with CEOs and production managers of small wine firms within New South Wales, South Australia, Western Australia and Victoria', Empirical study undertaken for this and other papers, 2006-07. Summary results available in: D. Aylward and M. Zanko, 'Reconfigured domains: alternative pathways for the international wine industry', International Journal of Technology, Policy and Management, 8, 2, 2008, pp. 148-56; D. Aylward, 'Differentiation or path dependency: a critical look at the Australian wine industry', Strategic Change, 16, 2007a, pp. 385-98; D. Aylward, 'Innovation and inertia: the emerging dislocation of imperatives within the Australian wine industry', International Journal of Technology and Globalization, 3, 2/3, 2007b, pp. 246-62.

2. B. J. Sommers, The Geography of Wine, Plume, New York, 2008, pp. 135-8, 253.

3. S. Charters, Wine and Society: The Social and Cultural Context of a Drink, Elsevier, Amsterdam, 2006, pp. 25-209.

4. H. Johnson, Wine: A Life Uncorked, Weidenfeld \& Nicolson, London, 2006, pp. 38-45.

5. I. Pretorius, 'The tailoring of designer grapevines and wine yeasts for a market-directed and quality focussed wine industry', paper delivered at the Institute for Wine Biotechnology, Department of Viticulture and Oenology, Stellenbosch University, South Africa, 2003, p. 1; B. Croser, 'Brand or authenticity', Australian and New Zealand Wine Industry Journal, December 2004, p. 22.

6. D. Aylward and M. Clements, 'Crafting a local-global nexus in the Australian wine industry', Journal of Enterprising Communities, 2, 1, 2008, pp. 85-7.

7. Ibid.

8. Grape and Wine Research and Development Corporation (GWRDC), Annual Report, Adelaide, 2007, pp. 2-12.

9. Aylward, 2006-07, op. cit. 
10. D. Aylward, 'Innovation lock-in: unlocking research and development path dependency in the Australian wine industry’, Strategic Change, 15, 2006, pp. 361-72.

11. P. Matthews, Real Wine: The Rediscovery of Natural Winemaking, Octopus, London, 2000, pp. 55-80, 110-50, 210-35.

12. Ibid.

13. K. Lynch, Adventures on the Wine Route, North Point Press, New York, 1998, pp. 58-9, 110-55, 189-212.

14. R. Gibson, 'Filtration: the game has changed', Wine Business Monthly, Adelaide, 2008, p. 58; Matthews, op. cit.

15. Ibid.

16. Lynch, op. cit., pp. 110-22.

17. M. Ritson, 'Tesco warns on wine boom crash', Sydney Morning Herald, 7 December 2007, p. 27.

18. T. Atkins, 'Four bottles to toast Australia’s wine wizard', Observer, 17 September 2006.

19. Aylward, 2006-07, op. cit.

20. Winemakers Federation of Australia, Directions 2025, Adelaide, 2007, pp. 2-12; Croser, op. cit.

21. Ritson, op. cit.

22. P. Fuller, 'Champers tastes may kill golden goose', Wine Business Magazine, April 2008, p. 12.

23. Ibid.

24. Ibid.

25. For example, D. Gaiter and J. Brecher, The Wall Street Journal Guide to Wine: New and Improved: How to Buy, Drink and Enjoy Wine, Random House, New York, 2002, pp. 32-6; Atkins, op. cit.; Ritson, op. cit.; F. Carter, 'The Australian wine industry could become a victim of its own successful marketing’, Melbourne Age, 2005, p. 31.

26. Winetitles, The Australian and New Zealand Wine Industry Directory, Adelaide, 2008, p. 16.

27. L. Stanford, 'Export volumes down', Wine Business Magazine, April 2008, p. 10.

28. Ibid.

29. R. Ulin, 'Invention and representation as cultural capital', American Anthropologist, 97, 3, 1995, pp. 519-24.

30. W. Echikson, Noble Rot: A Bordeaux Wine Revolution, WW Norton, London, 2004, pp. 2-24.

31. A. Duncan and D. Greenaway, 'The economics of wine-introduction', Economic Journal, 118, 2008, pp. F138-9.

32. Aylward, 2006-07, op. cit.

33. D. Kladstrup and P. Kladstrup, Champagne: How the World's Most Glamorous Wine Triumphed Over War and Hard Times, Harper Perennial, New York, 2005, pp. 78, 86, 93, 119.

34. G. Geursen and R. Rentschuler, The New Wave: Entrepreneurship \& the Arts, Melbourne, 2002, pp. 5-6.

35. See Craig Calhoun, Edward LiPuma and Moishe Postone (eds), Bourdieu Critical Perspectives, University of Chicago Press, Chicago, 1993, pp. 25-9; J. Guillory, Cultural Capital: The Problem of Literary Canon Formation, University of Chicago Press, Chicago, 1993, pp. 46-9.

36. J. Holden, Capturing Cultural Value: How Culture Has Become a Tool of Government Policy, DEMOS, London, 2004, pp. 3-9.

37. S. Ritnour, 'Economics and culture. By David Throsby', Quarterly Journal of Austrian Economics, 6, 2, 2003, pp. 103-6.

38. H. Hoegh-Guldberg, The Arts Economy 1968-1998: Three Decades of Growth in Australia, Australia Council, 2000, pp. 2-12.

39. D. Throsby, Economics and Culture, Cambridge University Press, Cambridge, 2001, p. 4.

40. Ibid.

41. Kladstrup and Kladstrup, op. cit.

42. Aylward, 2006-07, op. cit.

43. Aylward and Zanko, op. cit.; Aylward, 2007a, op. cit., pp. 385-98.

44. Johnson, op. cit., pp. 16, 35-45.

45. O. Gergaud and V. Ginsburgh, 'Natural endowments, production technologies and the quality of wines in Bordeaux. Does terroir matter?’, Economic Journal, 118, 2008, pp. F142-4.

46. Kladstrup and Kladstrup, op. cit., pp. 97-9. 
47. Aylward, 2006--07, -cit.

48. S. Tepper, 'Creative assets and the changing economy', Journal of Arts, Management, Law, and Society, 32, 2, 2002, pp. 159-68; Throsby, -cit.

49. Kladstmp and Kladstrup, — cit.

50. Ibid.

51. Croser, - cit. 